
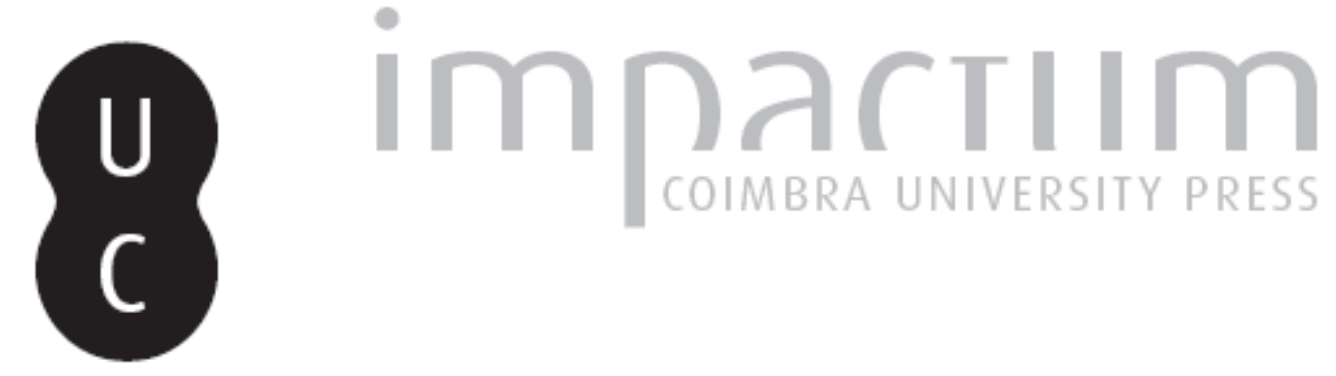

\title{
[Recensão a] ROBERT GOCZA, Onto-teo-logia. Status bytu realnego i mylnego w metafizyce Francisco Suáreza
}

Autor(es): $\quad$ Carvalho, Mário Santiago de

Publicado por: Faculdade de Letras da Universidade de Coimbra, Instituto de Estudos

URL

persistente: Filosóficos

DOI: DOI:http://dx.doi.org/10.14195/0872-0851_40_10

Accessed : $\quad$ 26-Apr-2023 14:05:13

A navegação consulta e descarregamento dos títulos inseridos nas Bibliotecas Digitais UC Digitalis, UC Pombalina e UC Impactum, pressupõem a aceitação plena e sem reservas dos Termos e Condições de Uso destas Bibliotecas Digitais, disponíveis em https://digitalis.uc.pt/pt-pt/termos.

Conforme exposto nos referidos Termos e Condições de Uso, o descarregamento de títulos de acesso restrito requer uma licença válida de autorização devendo o utilizador aceder ao(s) documento(s) a partir de um endereço de IP da instituição detentora da supramencionada licença.

Ao utilizador é apenas permitido o descarregamento para uso pessoal, pelo que o emprego do(s) título(s) descarregado(s) para outro fim, designadamente comercial, carece de autorização do respetivo autor ou editor da obra.

Na medida em que todas as obras da UC Digitalis se encontram protegidas pelo Código do Direito de Autor e Direitos Conexos e demais legislação aplicável, toda a cópia, parcial ou total, deste documento, nos casos em que é legalmente admitida, deverá conter ou fazer-se acompanhar por este aviso.

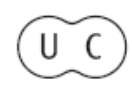




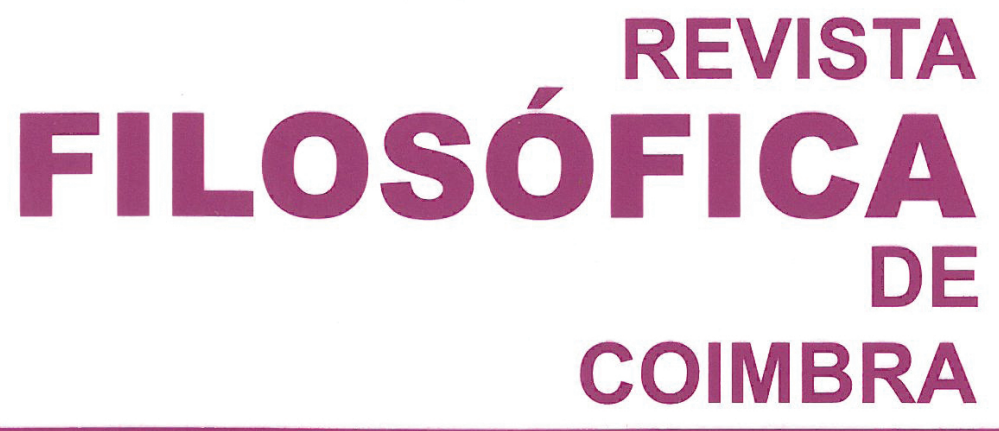

vol. 20 - número 40 - outubro 2011

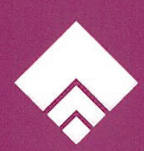




\section{RECENSÕES}

ROBERT GOCZAŁ, Onto-teo-logia. Status bytu realnego i myślnego w metafizyce Francisco Suáreza, Warszawa: Warszawska Firma Wydawnicza, 2011, $543 \mathrm{pp}$.

Apresentando-se como autor de várias publicações na área da metafísica e da filosofia do renascimento ibérico, o doutor Robert Goczał (leia-se: Gotxau) fez chegar à nossa redacção o seu mais recente trabalho com o título Onto-teologia. O estatuto do ser real e racional na metafísica de Francisco Suárez. Para a sua publicação a obra contou com o apoio do nosso Departamento, por óbvias razões (afinal Francisco Suárez foi professor na Universidade de Coimbra), como também de outras instituições nacionais e ibéricas, facto que o A. põe em evidência de várias maneiras (p.428), numa longa secção de Agradecimentos (pp. 426-33) reveladores do seu empenho, quer na feitura da obra, quer na sua promoção. Na dissertação ora em apreço lêem-se os seguintes capítulos: O homem e a obra (pp. 33-132); ontologia do ser real (pp. 133-236); ontologia do ser racional (pp. 237-339); classificação dos entes racionais (pp. 340-374); e, antes de encerrar, a discussão de três pontos de interpretação - provas da existência de Deus, mudança de paradigma na filosofia dos séculos XVI/XVII, explicação das questões controversas - procurando também evidenciar uma "nova perspectiva do conhecimento metafísico" assente na existência do absoluto sob a perspectiva da ontologia do ser racional (istnienie Absolutu w świetle ontologii bytu myślnego).

A monografia conta ainda com quatro apêndices - esquema das Disputas Metafísicas (pp. 438-40), índice geral do Comentário ao De Anima (441-48), índice da obra de Scoraille de 1917 (pp. 449-64) e o mesmo respeitante agora à obra de referência de 1999 de Jean-François Courtine (pp. 465-67) - e uma vasta, apesar de incompleta, bibliografia e índices (pp. 468- 543). Não compreendendo bem o relevo de todos estes apêndices - afinal o A. estudou sobretudo o principal tratado metafísico de Suárez, Disputationes Metaphysicae, juntamente com os Commentaria una cum quaestionibus in libros Aristotelis De Anima e o Index Lucupletissimus in Metaphysicam Aristotelis - percebe-se no entanto o diálogo 
privilegiado com a marcante tese de J.-F Courtine. Preocupado com a dificuldade do acesso à língua polaca por parte dos seus eventuais leitores ibéricos, o A. agrega um sumário no nosso idioma (pp. 434-37), embora algo descuidado na tradução. Como se evidencia no próprio título, o objecto do livro constitui um dos pontos nucleares da metafísica suareziana - a ontologia do ser real e racional compreendida no amplo contexto sistemático da metafísica e da teologia de eminente jesuíta - vertida numa análise exegético-reconstrutiva preocupada em descrever e em esclarecer, como dissemos, o principal tratado metafísico de Suárez, Disputationes Metaphysicae. O A. visa demonstrar o modo como devem ser compreendidas a génese e o estatuto da ontologia do ser real e racional no quadro do saber metafísico, ao mesmo tempo que avança com uma perspectiva filosófico-teológica de interpretação. Partindo da convicção de que somente a complexa explicação de todos os contextos (metafísicos, lógicos, semióticos, teológicos, doutrinais) permite situar adequadamente as teorias em causa no âmbito dos principais pressupostos da metafísica de F. Suárez, o A. acentua devidamente a ligação suareziana da teologia com a metafísica e esforça-se por evidenciar um compacto e coerente sistema de concepções sobre a ontologia do ser real. De facto, sustenta, sendo o objecto da metafísica o "ens inquantum ens reale", a essência (essentia) e a teologia (Deus, concebido na metafísica sob o aspecto dos princípios transcendentais e entendido justamente como limite da cognição humana) articulam-se permitindo uma descrição da metafísica de Suárez como uma "onto-teo-logia" em sentido próprio. A tese não é nova, evidentemente, e o tema tem sido amplamente debatido, como se vê, v.g., pelo elegante e bem informado estudo de Marco Forlivesi (Quaestio 5: 2005) que o A. compreensivelmente não podia chegar a conhecer (importaria aliás também citar o substancialíssimo número de Medioevo (Pádua) intitulado "I dibattiti sull'oggetto della metafísica dal tardo medioevo alla prima età moderna", 34: 2009). A tese polaca gira, então, em torno da concepção do "ser racional" (ens rationis), para o que foi concedida uma atenção especial à análise introdutória da concepção de "ser" na metafísica de F. Suárez, com o intuito de levar a compreender a estrutura do objecto do intelecto (ordo obiectivus) e da supertranscendentalidade (supratranscendentalis). Analisando as clássicas definições de ens rationis o A. demonstra que o ser racional não é um ser verdadeiro, pois depende das actividades do intelecto. "Ademais, demonstra que o ser racional não faz parte de nenhuma relação real que observamos no mundo natural. Um ser desta espécie simplesmente não existe fora do pensamento, caso em que se afirma que não existe objectivamente, mas apenas ao nível da intenção segunda do intelecto, sendo assim, em contraposição ao ser real ou físico. O segundo nível do intelecto (intenção segunda) é determinado em oposição ao primeiro nível (intenção primeira), que é a própria abstracção. O termo da intenção primeira é aquele que se refere ao objecto na verdadeira ordem natural. O termo intenção segunda é aquele que se refere ao objecto que existe na ordem intencional, ou seja, nas abstracções puras 
do intelecto. É o objecto que tanto a metafísica quanto a lógica tratam como uma forma específica do ser psíquico. O A. apresentou também uma análise dos motivos causadores do ser real e racional. Provou também que o acto causador não é directamente um acto cognitivo, mas um acto cognitivo reflexivo, também chamado actividade comparativa do intelecto." Outra preocupação apreciável que se detecta na monografia diz respeito ao enquadramento da metafísica de F. Suárez confrontando-a com as diferenças em relação à tradição aristotélicotomista (como Avicena, Averróis, São Tomás de Aquino, João Duns Escoto, Guilherme de Ockham, João Buridano), além do esforço por situar o nosso Jesuíta no contexto do seu meio histórico e intelectual, ambos fundamentais para a compreensão das bases escolásticas e modernas de tal concepção metafísica. Além de Gabriel Vázques, Pedro da Fonseca, Domingo Báñez, Hurtado de Mendoza, Roderigo de Arriaga, Francisco Toledo (Toletus), Luis de Molina e João de São Tomás, Suárez aparece-nos como um dos mais célebres representantes da filosofia do renascimento espanhol, nomeadamente porque, libertando-se dos comentaristas aristotélico-tomistas clássicos, pôde abranger o sistema na totalidade. Isto equivaleu a dotar-se de uma concepção mais geral em vez de uma interpretação lógica ou análise metafísica tradicional. De acordo com as disposições de Suárez, na interpretação do A. polaco, o saber metafísico deve também ser amparado no conhecimento da essência da própria compreensão e sabedoria de todas as teorias metafísicas, cujo sentido e valores permitem analisar com precisão as estruturas do mundo e do ser. Um segundo ponto a que o A. se atém liga-se, depois, à tentativa de determinar mais de perto o carácter da relação, que nas Disputationes se entretece entre a metafísica e a teologia (onto-teologia). Para o efeito o A. "orientou-se para a afirmação de que a base da unidade da filosofia e da teologia em Suárez assenta no princípio de que o conhecimento filosófico de Deus é possível, pois os princípios fundamentais constituem o fundamento ontológico de todo o ser e a verdade no conhecimento, e demonstrou que a teologização da metafísica, tal como a encontramos em Suárez, permite compreender melhor a essência da sua filosofia e, acima de tudo, a essência de sua metafísica". Por fim, somos informados que na "literatura filosófica polaca é escassa a existência de monografias que tratem de Francisco Suárez e da sua filosofia, o qual, afinal, influenciou de modo muito significativo a actividade filosófica moderna contemporânea. Em razão disto, lê-se, o livro aqui apresentado é uma monografia aguardada e que enriquece de forma significativa a literatura filosófica polaca."

Mário Santiago de Carvalho 